\title{
Fifth BCS-IRSG Symposium on Future Directions in Information Access (FDIA 2013)
}

3 September 2013

Granada, Spain

\author{
Editors \\ Leif Azzopardi \\ Liadh Kelly \\ Pablo Castells \\ Juan M. Fernández-Luna \\ Juan F. Huete
}




\section{Abstract}

In 2007, the 1st BCS-IRSG Symposium on Future Directions in Information Access (FDIA) was established to provide a forum for early career researchers to present, share and discuss their research ideas. The symposium was run in conjunction with the 6th European Summer School in Information Retrieval (ESSIR), which was held in Glasgow. Since then the symposium has been run numerous times as part of the ESSIR.

The objectives of the symposium are:

$>$ to provide an accessible forum for early researchers (particularly PhD students, and researchers new to the field) to share and discuss their research;

$>$ to create and foster formative and tentative research ideas;

$>$ to encourage discussion and debate about new future directions.

\section{Sponsors:}

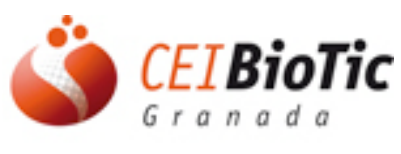

Fundación General UGR-Empresa
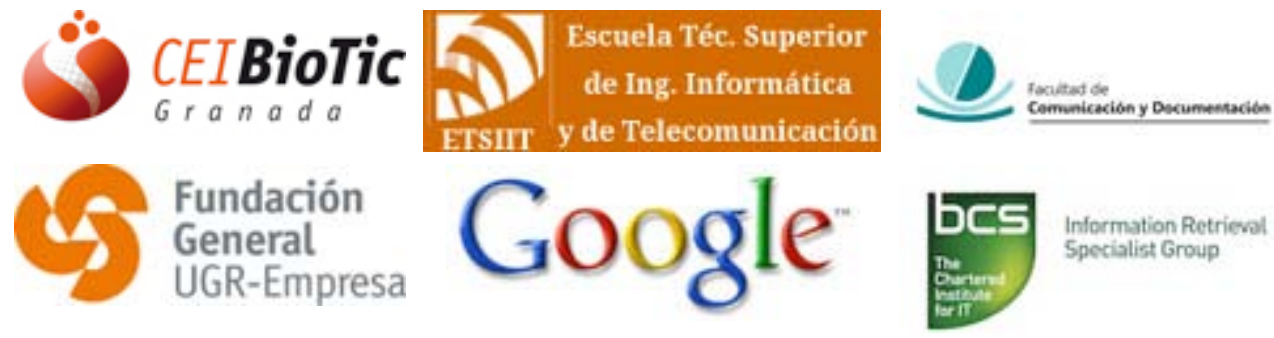

Information Retrieval Specialist Group
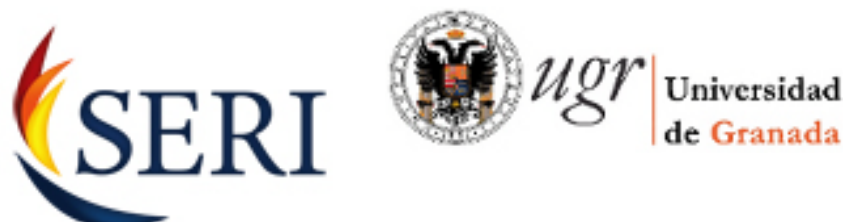

\section{YAHOO!}
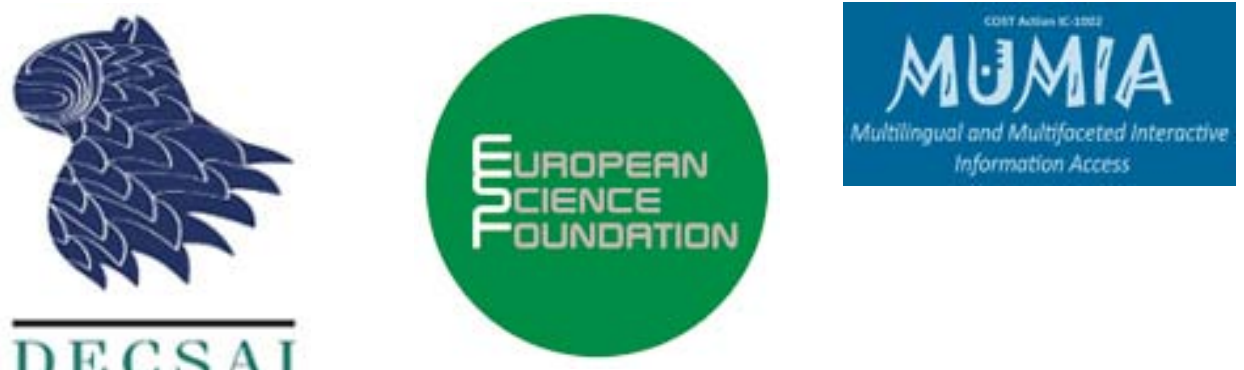

DECSAI

Departamente de Cieacias

de la Computacion e I. 


\section{Full Synopsis}

These proceedings contain papers and posters presented at the 5th Symposium on Future Directions in Information Access, held in Granada, Spain on the 3rd of September during the 2013 European Summer School in Information Retrieval (ESSIR). Each of the students gave a short seven minute presentation during the day and participated in a number of interactive sessions, where cross-pollination of ideas was encouraged and advice about doing a PhD was provided during a Q\&A session. To provide inspiration from an up and coming researcher, this years' keynote speaker was Dr Milad Shokouki from Microsoft Bing. Milad shared his opinions and thoughts with the students on how he approached his PhD and how he came up with a number of recipes to cook up his dissertation.

The organisers would like to thank the programme committee for their time and effort in providing detailed reviews and helpful advice to students on how to improve their work. We are grateful for the support and assistance from our organising institutes: SERI, MUMIA, UGR-Empresa, and the BCS-IRSG, as well as all the volunteers that helped out on the day. We would also like to thank all the sponsors for supporting Future Directions in Information Access and the European Summer School on Information Retrieval (listed alphabetically): BCS's Information Retrieval Specialist Group (BCS-IRSG), CEI BioTic Granada, Departmento de Clenclas de la Computacion e I.A at the University of Granada (DECSAI), European Science Foundation, Escuela Tec. Superior de Ing. Infomatic y de Telecmunication (ETSIIT), Facultad de Comunicacion y Documentacion, Google, Universidad de Granada and YAHOO! Labs.

We would also like to thank the BCS eWiCs service, and in particularly Jutta Mackwell for her help and assistance publishing the proceedings. 


\section{Editors}

Leif Azzopardi

Liadh Kelly

Pablo Castells

Juan M. Fernández-Luna

Juan F. Huete 


\section{Committee}

\section{General Chairs}

Pablo Castells, Universidad Autónoma de Madrid, Spain

Juan M. Fernández-Luna, Universidad de Granada, Spain

Juan F. Huete, Universidad de Granada, Spain

\section{PC Chairs}

Liadh Kelly, Dublin City University

Leif Azzopardi, University of Glasgow

\section{Programme Committee}

Maristella Agosti, University of Padua

Giambattista Amati, Fondazione Ugo Bordoni

Bettina Berendt, K.U. Leuven

Fabio Crestani, University of Lugano

David Elsweiler, University of Regensburg

Juan M. Fernández-Luna, University of Granada

Norbert Fuhr, University of Duisburg-Essen

Martin Halvey, Glasgow Caledonian University

Kal Jarvelin, University of Tampere

Hideo Joho, University of Tsukuba

Gareth Jones, Dublin City University

Jaap Kamps, University of Amsterdam 
Udo Kruschwitz, University of Essex

Mounia Lalmas, Yahoo! Labs Barcelona

Monica Landoni, USI

Andrew Macfarlane, City University London

Massimo Melucci, University of Padua

Josiane Mothe, Institut de Recherche en Informatique de Toulouse

Michael Oakes, University of Sunderland

Iadh Ounis, University of Glasgow

Benjamin Piwowarski, CNRS / University Pierre et Marie Curie

Tamara Polajnar, University of Glasgow

Stephen Robertson, Microsoft Research Cambridge

Stefan Rueger, Open University

Paul Thomas, CSIRO

Jun Wang, University College London

Emine Yilmaz, Microsoft Research Cambridge 


\section{Papers:}

\section{Keynote}

Milad Shokouki PhD Recipes http://dx.doi.org/10.14236/ewic/FDIA2013.1

\section{Full Papers}

Azhar Alhindi Towards Profile-Based Document Summarisation for Interactive Search Assistance http://dx.doi.org/10.14236/ewic/FDIA2013.2

Juan David Millan Cifuentes Context modelling for serendipitous discoveries in exploratory mobile search over social media http://dx.doi.org/10.14236/ewic/FDIA2013.3

Manika Kar Summarization of Changes in Dynamic Text Collections http://dx.doi.org/10.14236/ewic/FDIA2013.4

Piero Molino Semantic Models for Re-ranking in Question Answering http://dx.doi.org/10.14236/ewic/FDIA2013.5

Katja Niemann Usage Context-based Object Recommendation http://dx.doi.org/10.14236/ewic/FDIA2013.6

Cagri Toraman News Selection with Topic Modeling $\quad$ http://dx.doi.org/10.14236/ewic/FDIA2013.7

David Vilares Sentiment analysis for reviews and microtexts based on lexico-syntactic knowledge http://dx.doi.org/10.14236/ewic/FDIA2013.8

\section{Short Papers}

Fawaz Alarfaj Adaptive Window Size Selection for Proximity Search http://dx.doi.org/10.14236/ewic/FDIA2013.9

Noa P Cruz Díaz Negation and Speculation Detection for Improving Information Retrieval Effectiveness http://dx.doi.org/10.14236/ewic/FDIA2013.10 
Ignacio Fernández-Tobías Mining the Social Semantic Web for making cross-domain

recommendations $\quad$ http://dx.doi.org/10.14236/ewic/FDIA2013.11

Alexandru Lucian Ginsca Estimating User Credibility in Multimedia Information Flows http://dx.doi.org/10.14236/ewic/FDIA2013.12

Parth Gupta On Dimensionality Reduction Techniques for Cross-Language Information Retrieval http://dx.doi.org/10.14236/ewic/FDIA2013.13

Mihai Lupu Credibility in Search Systems via Information Retrieval theory http://dx.doi.org/10.14236/ewic/FDIA2013.14

Francisco Rangel Author Profile in Social Media: Identifying Information about Gender, Age,

Emotions and beyond http://dx.doi.org/10.14236/ewic/FDIA2013.15 